\title{
Multi-Objective Joint Optimal Operation of Reservoir System and Analysis of Objectives Competition Mechanism: A Case Study in the Upper Reach of the Yangtze River
}

\author{
Mufeng Chen, Zengchuan Dong *, Wenhao Jia, Xiaokuan Ni@ and Hongyi Yao \\ College of Hydrology and Water Resources, Hohai University, Nanjing 210098, China; \\ chenmf@hhu.edu.cn (M.C.); wenhao@hhu.edu.cn (W.J.); hynxk@hhu.edu.cn (X.N.); yaohy@hhu.edu.cn (H.Y.) \\ * Correspondence: zcdong@hhu.edu.cn
}

Received: 28 October 2019; Accepted: 29 November 2019; Published: 1 December 2019

\begin{abstract}
The multi-objective optimal operation and the joint scheduling of giant-scale reservoir systems are of great significance for water resource management; the interactions and mechanisms between the objectives are the key points. Taking the reservoir system composed of 30 reservoirs in the upper reaches of the Yangtze River as the research object, this paper constructs a multi-objective optimal operation model integrating four objectives of power generation, ecology, water supply, and shipping under the constraints of flood control to analyze the inside interaction mechanisms among the objectives. The results are as follows. (1) Compared with single power generation optimization, multi-objective optimization improves the benefits of the system. The total power generation is reduced by only $4.09 \%$ at most, but the water supply, ecology, and shipping targets are increased by $98.52 \%, 35.09 \%$, and $100 \%$ at most under different inflow conditions, respectively. (2) The competition between power generation and the other targets is the most obvious; the relationship between water supply and ecology depends on the magnitude of flow required by the control section for both targets, and the restriction effect of the shipping target is limited. (3) Joint operation has greatly increased the overall benefits. Compared with the separate operation of each basin, the benefits of power generation, water supply, ecology, and shipping increased by $5.50 \%, 45.99 \%, 98.49 \%$, and $100.00 \%$ respectively in the equilibrium scheme. This study provides a widely used method to analyze the multi-objective relationship mechanism, and can be used to guide the actual scheduling rules.
\end{abstract}

Keywords: giant reservoir system; joint operation; multi-objective optimization; interaction relationship mechanism

\section{Introduction}

With the rapid development of urbanization and the population explosion, the demand for water resources is also increasing. It is predicted that compared with the global water consumption for energy sectors in 2012, it will increase by $85 \%$ in 2030 [1]. This makes the problem of water resources become one of the most important problems in the world today. Reservoirs, as a basic component of complex water resources systems, form part of engineering measures to store and redistribute natural water resources [2], which play a significant role in the allocation of river water resources. The operation of the reservoirs not only guarantees the flood control safety of the river, but also plays various roles in power generation, water supply, ecological environment maintenance, and navigation. In power systems, hydropower stations are used for peak shaving and frequency modulation because of their cleanliness and flexible switching dispatch [3]. However, because of bearing the influence of multiple benefits, their power generation capacity is often greatly limited [4]. Due to the different 
requirements for the water head and flow of hydropower stations between power generation and other benefit objectives, there exists mutual influence and interdependence among these benefit objectives [5]. Therefore, how to deal with the impact between these objectives and maximize the benefit of limited water resources is the focus and difficult point of current research. Many scholars have focused on the optimal operation of reservoirs and reservoir groups in specific areas.

Many algorithms can be used to solve reservoir optimal operation and water management problems with the development of computing ability; such algorithms can be classified as classic or evolutionary methods [6]. However, the classic methods always perform poorly in solving complex problems, which makes the evolutionary methods develop rapidly [7]. Therefore, evolutionary methods are frequently used in water management problems, such as particle swarm optimization (PSO) [8-10], genetic algorithm (GA) [11-13], and so on [14-16]. With the increase in the pursuit of multi-objective benefits by decision makers, the multi-objective optimization algorithms (MOEAs) have received more attention and been improved a lot, such as gravity search algorithm (GSA) [7], strength Pareto evolutionary algorithm (SPEA) [17], non-dominated sorting genetic algorithm-III (NSGA-III) [18], and so on. With the development and improvement of these methods, researchers have carried out plenty of research work on the multi-objective optimization of reservoirs. Cheng et al. [19] studied the flood control and water supply shortages with an integrated approach using an optimization model and Monte Carlo simulations in Da-Ha creek basin in Taiwan. Tilmant [20], $\mathrm{Wu}$, and Chen [21] made the reference of optimal dispatching for the balance between reservoir power generation and water supply in an irrigation area within the basin. Si at al. [22] analyzed the contradictory relationship between hydropower generation and water supply in the reservoir system of the trunk river basin, and constructed a water-energy-food model. Meng et al. [6] proposed an improved multi-objective cuckoo search algorithm and discussed the competition relationship between power generation and water supply of the Xiaolangdi cascade hydropower stations on the Yellow River. In addition, more and more water resources management, water allocation, and reservoir operation problems have also been studied [23-26].

In China, the water resources problem is also one of the most important strategic problems affecting the development of the country. The Yangtze River plays an irreplaceable role in promoting the economic and social development of our country [3], and the upper reaches of the Yangtze River, from the source to Yichang, Hubei Province, have huge potential hydropower development capacity and utilization value due to its large terrain difference and high flowrate volume. In the year 2018, 21 completed controlled reservoirs in the upper reaches of the Yangtze River were included in the joint flood control operation; about 11.1 billion $\mathrm{m}^{3}$ of flood was retained and stored by upstream reservoirs, and the total water supply was about 48.1 billion $\mathrm{m}^{3}$ until November [27]. They had made tremendous contributions to flood control and benefit development in the river basin. With the completion of a series of controlled reservoirs in the upper reaches of the Yangtze River, the maximization of the utilization value of water energy and water resources has become an important task of reservoir system development, and the optimal operation of reservoirs in the upper reaches of the Yangtze River is increasingly important [28].

At present, there has been some research on the optimal dispatching of reservoirs and the relationship between various benefit objectives in the upper reaches of the Yangtze River. Liu et al. [29] enhanced the flood control capacity and power generation benefits of the Three Gorges Reservoir in flood season by optimizing the sequence and quantity of spillway operation. Zhou et al. [30] studied the contradiction between flood control and water storage at the end of flood season of Jinsha River and the Three Gorges Reservoir. Jia [31], Wang [32], and Lu et al. [33] studied the relationship between power generation and ecology in Jinsha River cascade reservoirs and the Three Gorges cascade. In terms of multi-objective coordination and optimization, Zhou et al. [34] studied the competition among flood control, power generation, and shipping in the Three Gorges cascade and the comprehensive operation plan in flood season. Most of the existing studies choose the Three Gorges-Gezhouba cascade reservoirs or a single tributary cascade reservoir group in the upper reaches of the Yangtze 
River as the research area. Although these results can provide theoretical support for the optimal operation of reservoirs in a single basin, there is a lack of research on the joint optimal operation of the giant reservoirs system in the upper reaches of the Yangtze River, which causes a limitation in spatial breadth. These researches destroy the integrity and connectivity of the reservoir group system in the upper reaches of the Yangtze River [35]. In addition, current research studies mostly focus on no more than three objectives, which leads to deficiencies in integrity because the most basic benefits brought by the construction of hydropower stations include the five benefits of flood control, power generation, water supply, ecology, and shipping. The existing studies isolate the five benefits and lack of overall grasp of the mutual restriction among them, leading to a discount on the applicability of these optimal dispatching decisions.

Therefore, in view of the problems in recent studies, based on the Joint Regulation Scheme of the reservoir group in the upper reaches of the Yangtze River in 2018, a giant reservoir group system model including 30 controlled reservoirs that have been constructed, are under construction, or are planned in the upper reaches basin was built. Taking this system as the object, this paper studied the multi-objective joint optimal dispatching problem of a giant reservoir group system with four economic benefits of power generation, ecology, water supply, and shipping on the premise of meeting the flood control requirements. This model will be described in Sections 2 and 3. After analyzing the rationality of model calculation, this study explores the multi-objective optimal dispatching mode of the reservoir group system in the upper reaches of the Yangtze River, compares the similarities and differences of the multi-objective competition relations under different inflow conditions, and probes into the causes of the interaction of the benefit objectives. The advantages of joint optimal dispatching are also discussed. These analyses mentioned will be shown in Section 4 . The results of this study not only increase the comprehensive development benefit of the system on the premise of ensuring the scheduling requirements, but also provides some technical reference and theoretical support for the reservoir dispatching mode in the upper reaches of the Yangtze River to meet the different benefit demands for decision makers. Some suggestions for further study will be shown in Section 5 . The research process of this study is shown in Figure 1. 


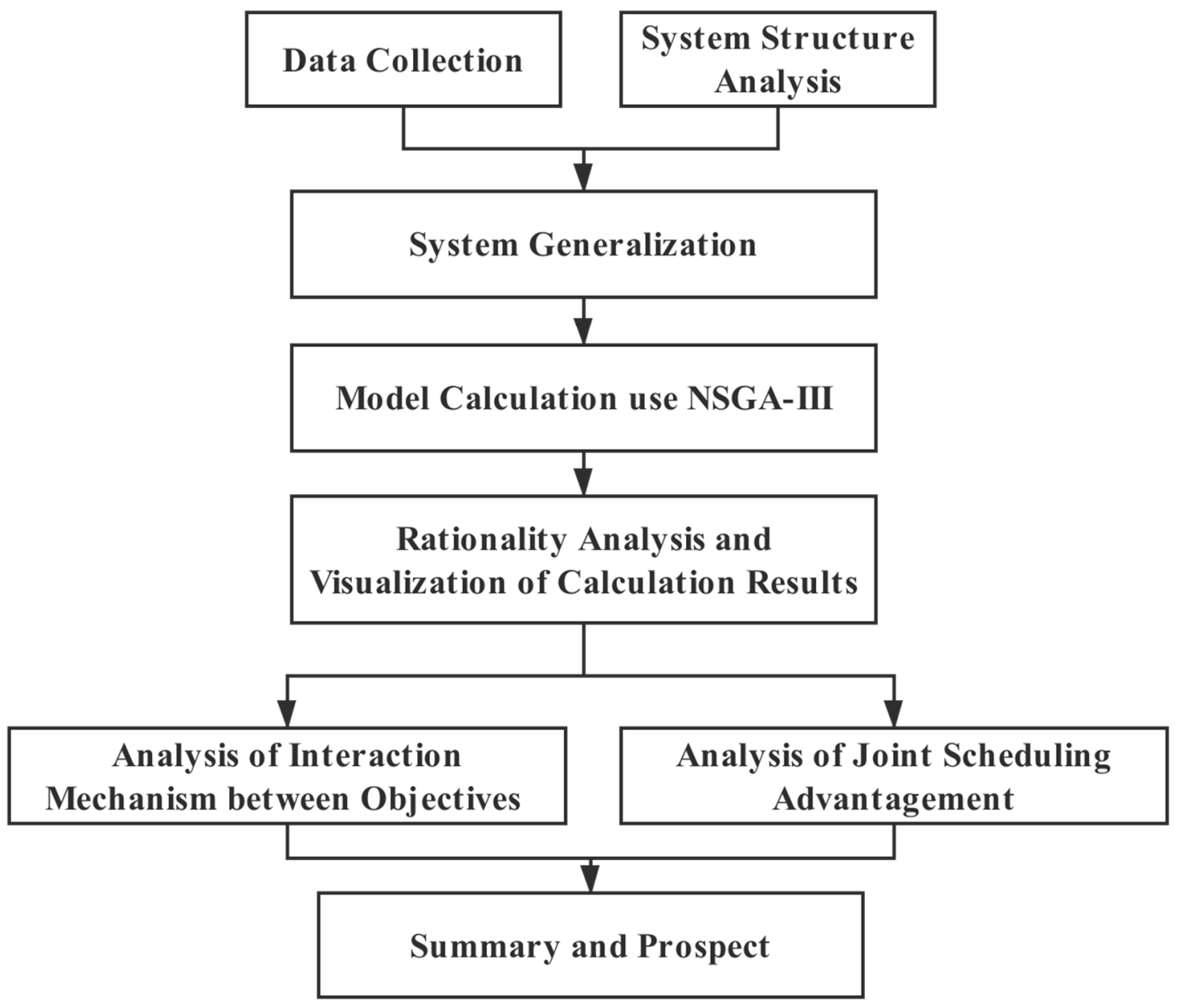

Figure 1. Flow chart of the research process of this study.

\section{Study Area}

The upper reaches of the Yangtze River, which controls about 1 million $\mathrm{km}^{2}$ of river basins, are well developed with abundant hydroelectric energy. The average annual runoff is over 450 billion $\mathrm{m}^{3}$, accounting for half of the total water resources in the whole Yangtze River basin. The built, under construction, and proposed controlled reservoirs in the upper reaches of the Yangtze River have gradually formed the joint operation pattern of the giant reservoir system in this area. However, reservoirs undertake many tasks at the same time, which require different water levels and discharge. Conflicts occur between these targets. The task of power generation requires high water level or large discharge. However, this may destroy the water supply demand if the inflow is stored in the reservoir to maintain the water level; or, the ecological requirement may be damaged if the discharge is much larger than the ecological suitable flow, as well as for shipping. Therefore, this paper is aimed at analyzing the relationship mechanism between these benefit targets and studying the joint operation of a giant reservoir system.

In this study, the observed data of hydrological station flow at the dam site of all the built, under construction, and proposed reservoirs were taken as basic data, and the monthly average water level was taken as the decision variable. Therefore, the hydropower stations with small regulation capacity, such as daily and weekly regulation hydropower stations, will be transformed into runoff hydropower stations. The fine scheduling process of these reservoirs is not considered, but their power generation is included in the total generation of the system to add these hydropower stations with smaller regulation capacity to the model calculation. The influence of the total generation of the reservoir group system on other profit-making objectives can be considered. 
The water units, storage and extraction work, control nodes, and channels in the reservoir group system were converted into points and lines based on analyzing the utilization and management of water resources in this system. According to the topological relationship, the system composed of these 20 reservoirs was generalized. The overview diagram is shown in Figure 2. The characteristics of the 20 reservoirs are listed in Table 1.

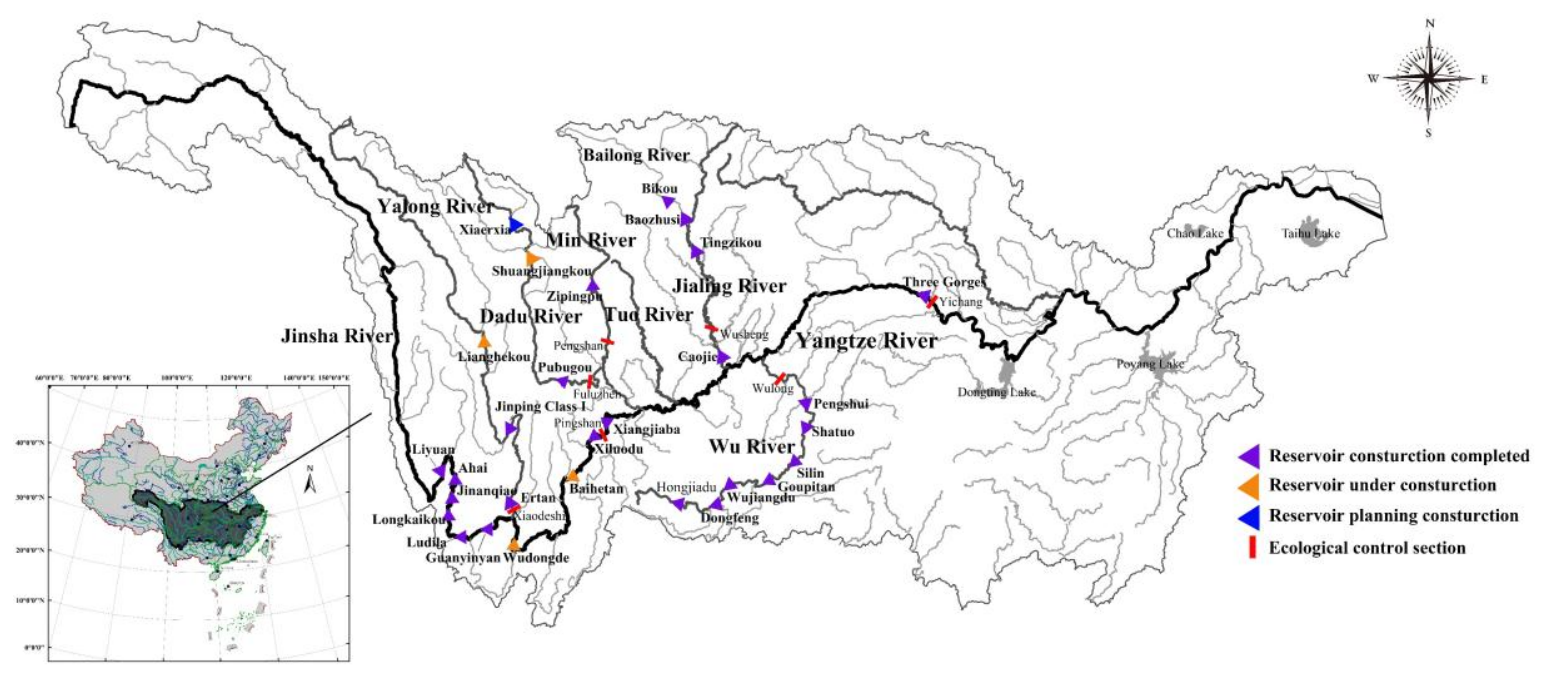

(a)

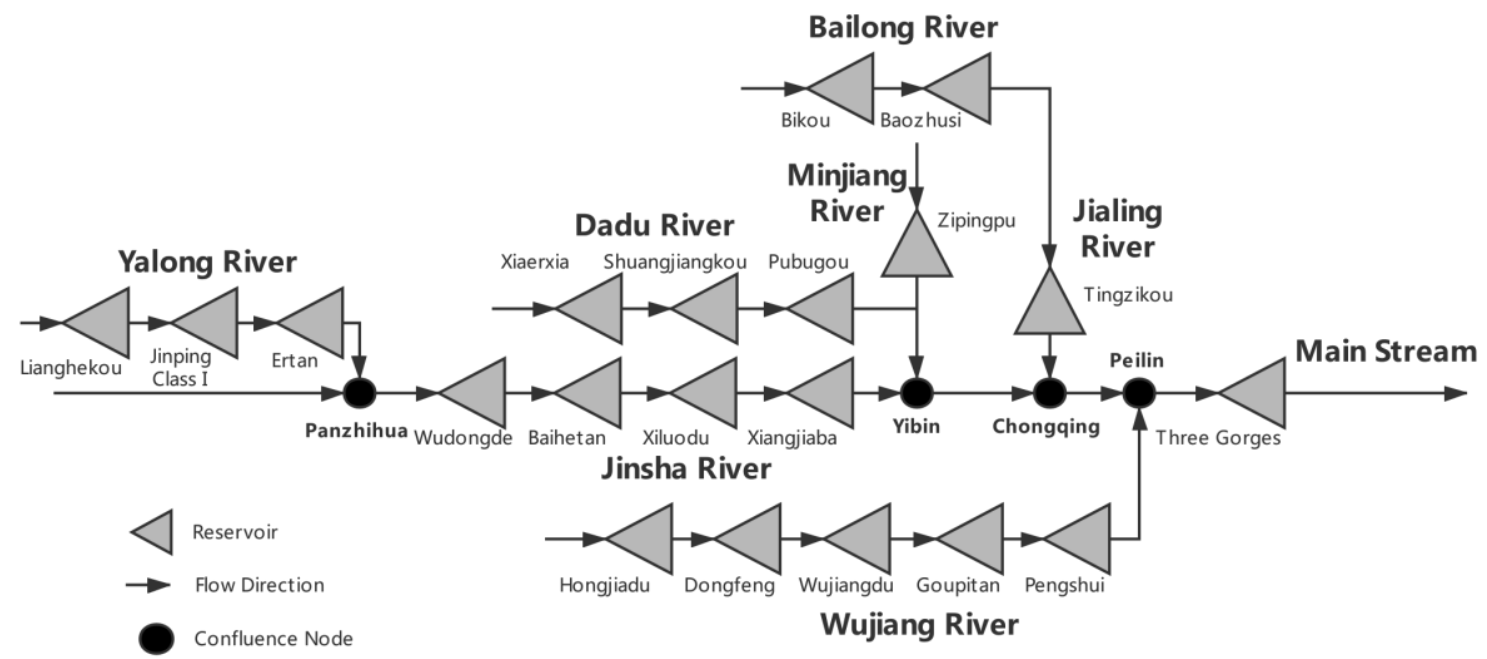

(b)

Figure 2. 20 controlled reservoir group systems in the upper reaches of the Yangtze River. (a) Geographical location of case study area; (b) Generalization diagram of the reservoir system. 
Table 1. List of characteristic parameter values of the reservoirs.

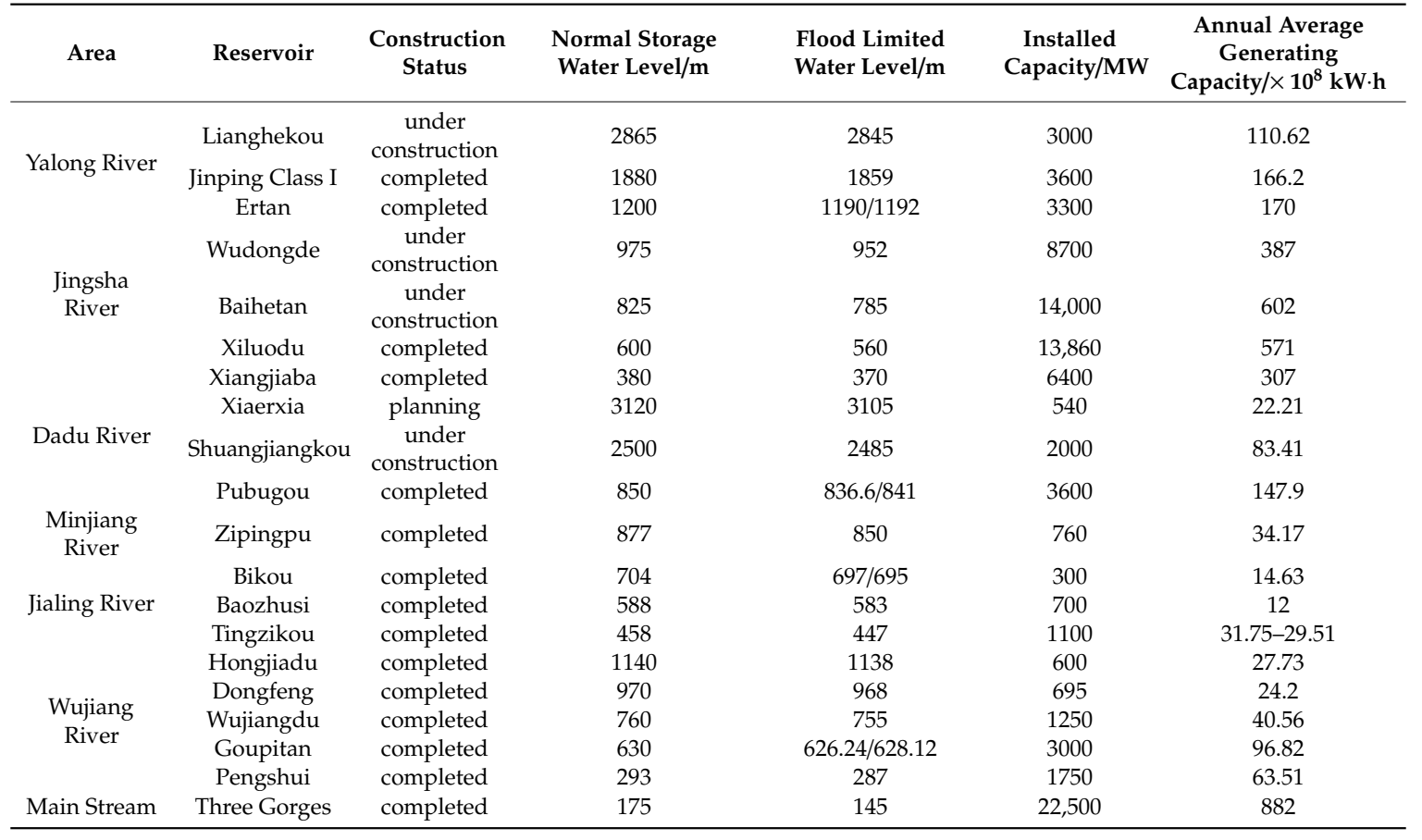

\section{Model and Solution}

\subsection{Objective Function}

In this study, the optimal operation objectives of reservoir groups in the upper reaches of the Yangtze River include the following five objectives: power generation, water supply, ecology, shipping, and flood control. The daily or lower step size of flood control fine operation is generally selected as the dispatching scale; however, it is inconsistent with the research step selected in this study. Meanwhile, if the flood control fine operation is considered, the dimensions of the model decision variables will be too large, and the calculation difficulty will be increased. Therefore, the flood control task of reservoirs is treated as the constraint condition to ensure that each reservoir is maintained at its flood limited water level during the flood season.

The objective functions for each target are expressed as follows.

(1). Power generation objective: maximum total power generation of reservoir system

$$
\begin{gathered}
\max f_{1}=\max E=\sum_{m=1}^{M} \sum_{t=1}^{T} N_{m}^{t} \times \Delta t \\
N_{m}^{t}=k_{m} \times q_{m}^{t} \times h_{m}^{t}
\end{gathered}
$$

where $f_{1}$ is the power generation objective function, $E$ is the total power generation of the reservoir system, $\mathrm{kW} \cdot \mathrm{h} ; N_{m}^{t}$ is the output of the $m$-th hydropower station in the $t$-th period, $\mathrm{kW} ; M$ is the total number of reservoirs; $T$ is the calculation period length, year; $k_{m}$ is the hydropower generation efficiency of the $\mathrm{m}$-th reservoir; $q_{m}^{t}$ is the power generation flow of the $m$-th hydropower station in the $t$-th period, $\mathrm{m}^{3} / \mathrm{s} ; h_{m}^{t}$ is the average hydropower head of the $m$-th reservoir in the $t$-th period, $m$; and $\Delta t$ is the unit calculation time step size, months. 
(2). Water supply objective: minimum water shortage

$$
\min f_{2}=\sum_{k=1}^{K} \sum_{t=1}^{T}\left(q_{t}-Q_{k t}\right)\left(q_{t}<Q_{k t}\right)
$$

where $f_{2}$ is the water supply objective function, $K$ is the number of socioeconomic water demand areas; $q_{t}$ is the reservoir water supply capacity in the $t$-th period, $\mathrm{m}^{3} / \mathrm{s} ; Q_{k t}$ is the flow rate of the $t$-th period corresponding to the total water demand of the $k$-th area, $\mathrm{m}^{3} / \mathrm{s}$. All the water demand data of each water supply control station are extracted from the regional yearbook and water resources bulletin, and are referred to the minimum control flow index of the basic water supply control section in the Yangtze River basin.

(3). Ecological objective: minimum suitable ecological flow deviation

$$
\min f_{3}=\sum_{l=1}^{L} \sum_{t=1}^{T}\left|R_{i t}-E_{i t}^{a p p}\right|
$$

where $f_{3}$ is the ecological objective function, $L$ is the total number of ecological control sections in river reach; $E_{i t}^{a p p}$ is the suitable ecological flow of section $l$ in period $\mathrm{t}, \mathrm{m}^{3} / \mathrm{s}$; and $R_{i t}$ is the real flow of section $l$ in period $t, \mathrm{~m}^{3} / \mathrm{s}$.

The suitable ecological flow of each ecological control section was calculated by the monthly frequency method [36], and the results are shown in Table 2.

(4). Shipping objective: minimum suitable navigable flow deviation

$$
\begin{gathered}
\min f_{4}=\sum_{s=1}^{S} \sum_{t=1}^{T} Q_{s t} \\
Q_{s t}= \begin{cases}q_{t}-S U^{a p p} & q_{t}>S U^{a p p} \\
0 & S L^{a p p}<q_{t}<S U^{a p p} \\
S L^{a p p}-q_{t} & q_{t}<S L^{a p p}\end{cases}
\end{gathered}
$$

where $f_{4}$ is the shipping objective function; $S$ is the total number of the channels; $Q_{s t}$ is the absolute value of the interval difference between the discharge and shipping suitable flow in each

\begin{tabular}{|c|c|c|c|c|c|c|c|c|c|c|c|c|}
\hline \multirow{2}{*}{ Control Sections } & \multicolumn{12}{|c|}{ Month } \\
\hline & 1 & 2 & 3 & 4 & 5 & 6 & 7 & 8 & 9 & 10 & 11 & 12 \\
\hline Xiaodeshi & 476 & 423 & 421 & 503 & 808 & 1899 & 3400 & 3082 & 3367 & 1972 & 1023 & 646 \\
\hline Pingshan & 1655 & 1400 & 1331 & 1469 & 2151 & 4532 & 9284 & 9283 & 9939 & 6117 & 3416 & 2167 \\
\hline Fuluzhen & 410 & 356 & 368 & 509 & 1016 & 2176 & 2726 & 2178 & 2223 & 1685 & 910 & 573 \\
\hline Pengshan & 133 & 114 & 135 & 226 & 427 & 672 & 915 & 747 & 645 & 454 & 258 & 177 \\
\hline Wusheng & 186 & 162 & 196 & 295 & 475 & 520 & 1290 & 927 & 1076 & 637 & 366 & 240 \\
\hline Wulong & 1135 & 1002 & 722 & 459 & 341 & 359 & 419 & 807 & 1675 & 2617 & 2643 & 1536 \\
\hline Yichang & 25,250 & 17,613 & 9450 & 5810 & 4308 & 3867 & 4217 & 6261 & 11,227 & 17,683 & 29,246 & 26,200 \\
\hline
\end{tabular}
calculation period, $\mathrm{m}^{3} / \mathrm{s}$; and $S U^{a p p}$ and $S L^{a p p}$ are the upper and lower bounds for the range of shipping suitable flow, which are defined by each channel dispatching procedure, $\mathrm{m}^{3} / \mathrm{s}$.

Table 2. List of each ecological control section's suitable ecological flow $\left(\mathrm{m}^{3} / \mathrm{s}\right)$.

Each channel's shipping suitable flow is shown in Table 3. 
Table 3. List of channel's shipping suitable flow $\left(\mathrm{m}^{3} / \mathrm{s}\right)$.

\begin{tabular}{ccccc}
\hline Location & Jinsha River & Jialing River & Wujiang River & Main Stream \\
\cline { 2 - 5 } & $\begin{array}{c}\text { Downstream of } \\
\text { Xiangjiaba }\end{array}$ & $\begin{array}{c}\text { Downstream of } \\
\text { Tingzikou }\end{array}$ & $\begin{array}{c}\text { Downstream of } \\
\text { Pengshui }\end{array}$ & $\begin{array}{c}\text { Downstream of } \\
\text { the Three Gorges }\end{array}$ \\
\hline $\begin{array}{c}\text { Suitable flow } \\
\text { range } / \mathrm{m}^{3} / \mathrm{s}\end{array}$ & $1200-12,000$ & $120-8000$ & $280-5000$ & $5000-56,700$ \\
\hline
\end{tabular}

\subsection{Constraint Condition}

(1). Water balance constraint

$$
\begin{gathered}
V_{m, t}-V_{m, t-1}=\left(I_{m, t}-Q_{m . t}\right) \times \Delta t \\
I_{m, t}=Q_{m-1, t}+I n_{m-1, t}-E_{m, t}
\end{gathered}
$$

where $V_{m, t}$ and $V_{m, t-1}$ are the storage capacity of the $m$-th reservoir at the end and the beginning of the $t$-th period, $\mathrm{m}^{3}$. The water level value of the reservoir can be deduced by $V$ according to the water level-storage capacity curve; and $I_{m, t}$ and $Q_{m, t}$ are the average inflow and outflow of the $m$-th reservoir in the $t$-th period, $\mathrm{m}^{3} / \mathrm{s}$. The outflow refers to the total amount of water discharge from the reservoir through all the gates and spillways to the downstream channel, regardless of the fine dispatching process during the flood season; $I n_{m, t}$ is the interval inflow between the $m$-th reservoir and the $(m+1)$-th reservoir in the $t$-th period, $\mathrm{m}^{3} / \mathrm{s} ; E_{m, t}$ is the lost flow of the $m$-th reservoir in the $t$-th period, which is mainly caused by the evaporation and infiltration in the process of water transfer between two reservoirs. $\mathrm{m}^{3} / \mathrm{s}$; and $\Delta t$ is the unit calculation time step size, months.

(2). Reservoir discharge limits

$$
Q_{m, t}^{\min } \leq Q_{m, t} \leq Q_{m, t}^{\max }
$$

where $Q_{m, t}^{\min }$ and $Q_{m, t}^{\max }$ are the minimum and maximum outflow of the $m$-th reservoir during the $t$-th period, $\mathrm{m}^{3} / \mathrm{s}$.

(3). Reservoir water-level limits

Each reservoir should meet the water level limit in every period of operation.

$$
Z_{m, t}^{\min } \leq Z_{m, t} \leq Z_{m, t}^{\max }
$$

where $Z_{m, t}^{\min }$ is the minimum water level of the $m$-th reservoir during the $t$-th period, which is equal to the flood limited water level, $m ; Z_{m, t}^{\max }$ is the maximum water level of the $m$-th reservoir during the $t$-th period, which is equal to the flood control water level during the flood season and equal to the normal storage water level during the non-flood season, $m$. According to the documents of the General Command of Flood Control and Drought Relief of the Yangtze River, the period of the flood season is shown in Table 4. 
Table 4. Period of flood season of each reservoir; the reservoir water level should be kept at the flood control water level during this period.

\begin{tabular}{ccc}
\hline Area & Reservoir & Time \\
\hline Yalong River & $\begin{array}{c}\text { Lianghekou } \\
\text { Jinping Class I } \\
\text { Ertan }\end{array}$ & JUN-JUL \\
& Wudongde & \\
& Baihetan \\
Xiluodu & Jiangjiaba & \\
Jingsha River & Xiaerxia & \\
& Shuangjiangkou & \\
& Pubugou & JUN-SEP \\
Dadu River & Zipingpu & JUN-SEP \\
& Bikou & MAY-SEP \\
\hline Minjiang River & Baozhusi & JUN-SEP \\
\hline \multirow{2}{*}{ Jialing River } & Tingzikou & JUN-AUG \\
& Hongjiadu & \\
\hline & Dongfeng & JUN-AUG \\
& Wujiangdu & \\
\hline Wujiang River & Goupitan & MAY-AUG \\
& Pengshui & JUN-SEP \\
\hline Main Stream & Three Gorges &
\end{tabular}

(4). Power generation limits

The actual output of the reservoir shall meet the output limit in every period of operation.

$$
N_{m, t}^{\min } \leq N_{m, t} \leq N_{m, t}^{\max }
$$

where $N_{m, t}^{\min }$ and $N_{m, t}^{\max }$ are the minimum and maximum power limit of the $m$-th reservoir during the $t$-th period, $10^{4} \mathrm{~kW}$.

\subsection{Model Solving}

In this study, the NSGA-III algorithm is adopted, which is improved in detail based on the framework of the original NSGA-II algorithm using reference points to select better individuals. The method of the normal boundary intersection point proposed by Das and Dennis is used to determine reference points [37]. This improvement makes the optimal solution more uniformly distributed on the non-dominant layer when solving the high-dimensional target problem, and effectively prevents the algorithm from falling into local optimum [18]. This method is widely used in multi-objective optimization problems [38,39]. In addition, in order to evaluate the optimization effect of the multi-objective optimization model for each benefit target, the PSO was used to optimize the maximum power generated in the reservoir system.

Figure 3 shows the flow chart of NSGA-III and PSO. 


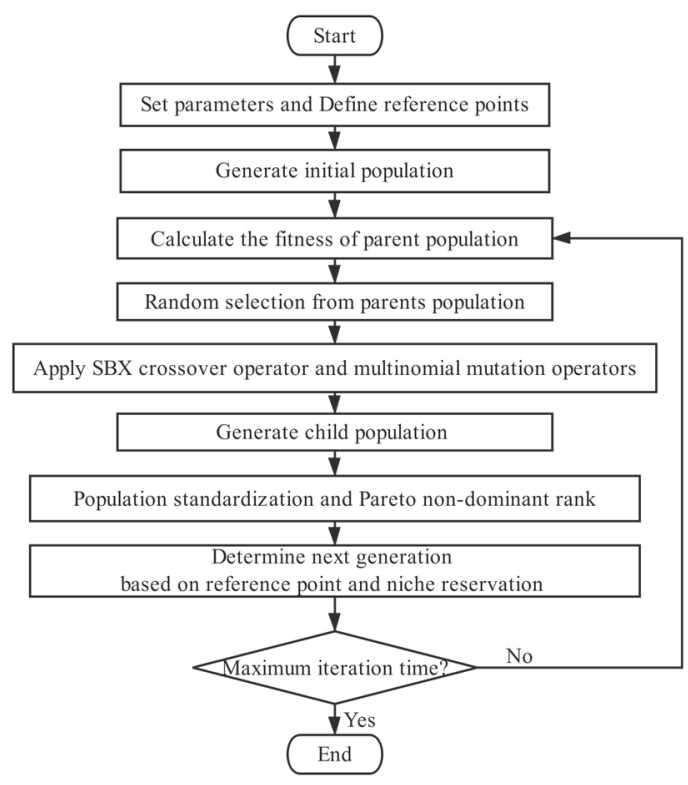

(a)

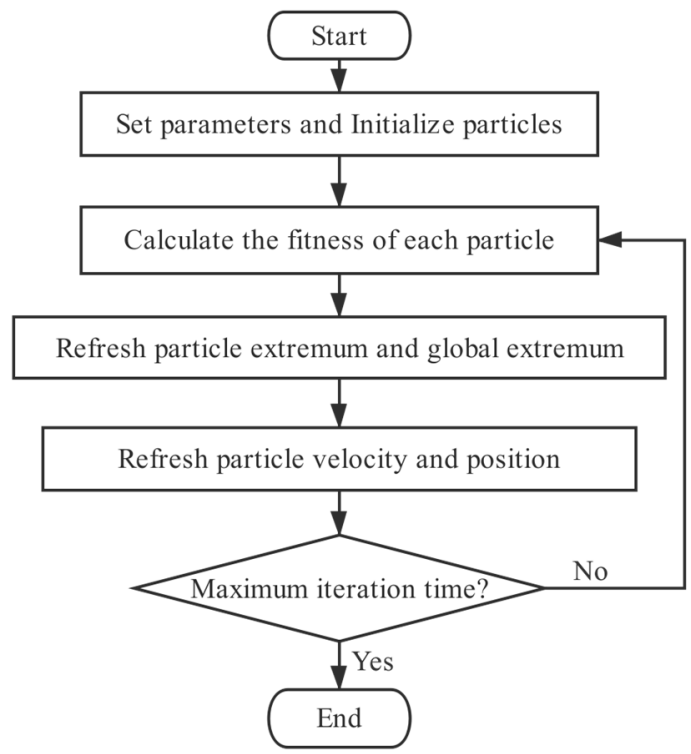

(b)

Figure 3. Flow chart of non-dominated sorting genetic algorithm-III (NSGA-III) and particle swarm optimization (PSO). (a) NSGA-III; (b) PSO.

In this study, the platEMO2.0 platform written by Ye Tian [40] and other scholars is used as the carrier to solve the multi-objective optimization calculation. The annual runoff in the upper reaches of the Yangtze River is calculated by frequency and the year, with a corresponding frequency of $25 \%$, $50 \%$, and $75 \%$ being selected as a typical year for wet (1964), normal (1988), and dry (1959). The average monthly water level values in three typical years were taken as the decision variables, the number of decision variables was 240 , the population size was 120 , and the number of iterations was 10,000 . In order to make the optimal operation results more in line with the requirements in the actual operation, the starting and ending regulation water levels were both set as the normal storage water level. However, the total amount of water is small after the flood season in the dry year, so it is hard to return to the normal storage water level at the end of the calculation period. Meanwhile, this study paid more attention to benefit optimization of the reservoir group system. Therefore, the water level was not strictly limited to the normal storage level in the last calculation period in the dry year.

The conception of hyper volume (HV) was used to prove the convergence of the model under the given time of iterations in this study. HV is the only unary measure used to measure the size of the dominant region of a non-dominant solution set [41] and to prove that one set of non-dominant solutions is not inferior to another. In this kind of discrete multi-objective optimization problem, the $\mathrm{HV}$ value will gradually maximize and stabilize with the increase of iteration time if and only if the solution set is the Pareto optimal solution [42].

In this study, the most disadvantageous points (the minimum power generation value and the maximum damage rate of ecology, water supply, and shipping) were set as the reference point to calculate the HV values of different evolution times. The trend curve is shown in Figure 4. It shows that when the evolution time reaches 6000 generations, the HV value began to be stable. This proves the convergence of the algorithm under the designed times of iterations, and the final set of solution can be considered as the Pareto optimal solution. 


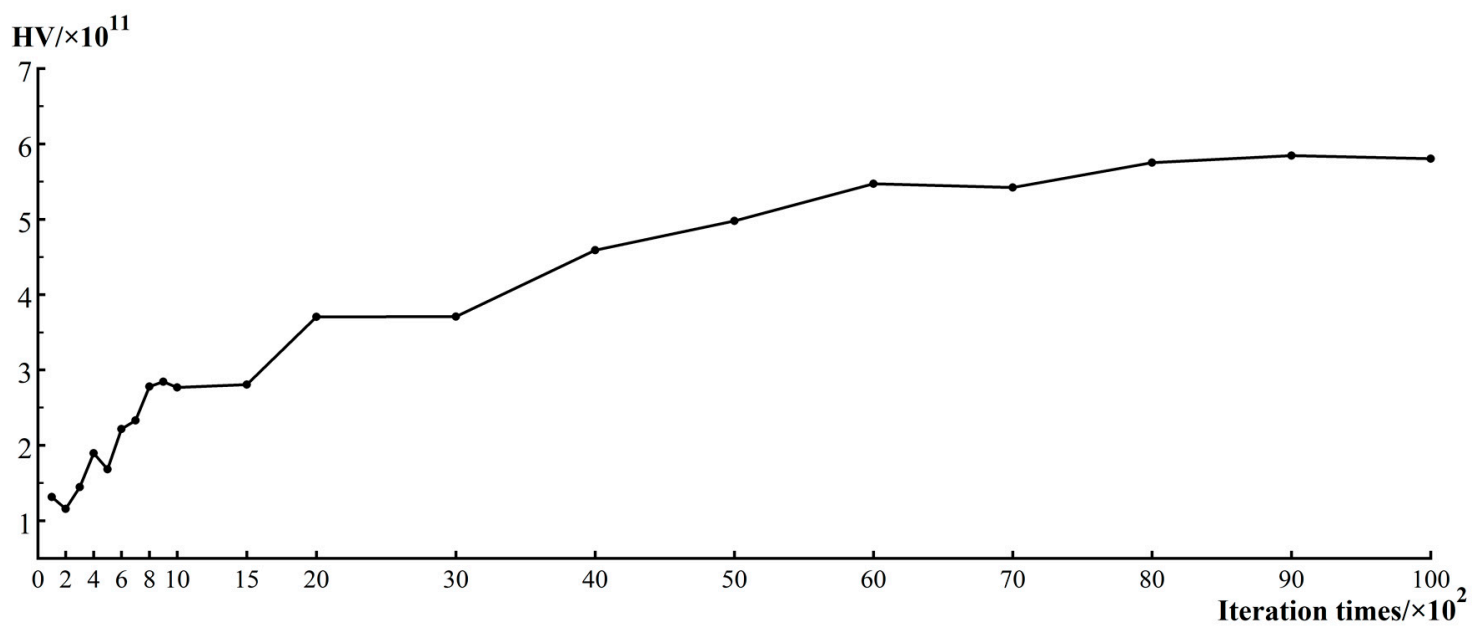

Figure 4. Hyper volume (HV) value trend curves of the model under different evolution numbers.

\section{Results and Discussion}

\subsection{Advantage Analysis of Multi-Objective Optimization}

In order to verify the rationality of the calculation results, this study uses PSO to calculate the total power generation of the reservoir system in the upper reaches of the Yangtze River and compares the value of each benefit objective in the single-objective and multi-objective optimization.

The comparison results are shown in Table 5 below.

Table 5. Comparison of single-objective and multi-objective optimization results for total power generation of reservoir system.

\begin{tabular}{|c|c|c|c|c|c|c|}
\hline \multirow{2}{*}{ Objective } & \multicolumn{2}{|c|}{ Wet Year (1964) } & \multicolumn{2}{|c|}{ Normal Year (1988) } & \multicolumn{2}{|c|}{ Dry Year (1959) } \\
\hline & Single & Multiple & Single & Multiple & Single & Multiple \\
\hline $\begin{array}{c}\text { Power generation } / \times 10^{11} \\
\mathrm{~kW} \cdot \mathrm{h}\end{array}$ & 5.69 & $\begin{array}{c}5.56 \\
(-2.82 \%)^{1}\end{array}$ & 5.09 & $\begin{array}{c}4.84 \\
(-4.09 \%)\end{array}$ & 4.63 & $\begin{array}{c}4.61 \\
(-0.43 \%)\end{array}$ \\
\hline Water shortage $/ \mathrm{m}^{3} / \mathrm{s}$ & 8652 & $\begin{array}{c}128 \\
(+98.52 \%)^{2}\end{array}$ & 5415 & $\begin{array}{c}570 \\
(+89.47 \%)\end{array}$ & 9689 & $\begin{array}{c}584 \\
(+93.97 \%)\end{array}$ \\
\hline $\begin{array}{c}\text { Suitable ecological flow } \\
\text { deviation } / \times 10^{5} \mathrm{~m}^{3} / \mathrm{s}\end{array}$ & 1.14 & $\begin{array}{c}0.74 \\
(+35.09 \%)\end{array}$ & 0.81 & $\begin{array}{c}0.59 \\
(+27.16 \%)\end{array}$ & 0.90 & $\begin{array}{c}0.77 \\
(+14.44 \%)\end{array}$ \\
\hline $\begin{array}{c}\text { Suitable navigable flow } \\
\text { deviation } / \mathrm{m}^{3} / \mathrm{s}\end{array}$ & 2150 & $\begin{array}{c}0 \\
(+100.00 \%)\end{array}$ & 106 & $\begin{array}{c}0 \\
(+100.00 \%)\end{array}$ & 114 & $\begin{array}{c}88 \\
(+22.81 \%)\end{array}$ \\
\hline
\end{tabular}

${ }^{1}$ The percentage represents the ratio of the multi-objective optimization benefit change value to that of the single objective optimization. ${ }^{2}$ The positive percentage indicates that the target benefit is increased, while the negative percentage indicates that the benefit is reduced.

The actual annual average electricity generation is about $4.68 \times 10^{11} \mathrm{~kW} \cdot \mathrm{h}$. The amount is less than that after optimizing in the wet year and the normal year and just $1.52 \%$ more than that in the dry year, indicating that the model did increase the benefit of the system. It can be seen from the table that the total system power generation of single-objective optimization is larger than that of multi-objective optimization. This is because the other three benefit objectives have an impact on the total amount of system power generation in multi-objective optimization. The requirements for reservoir discharge and water head are different, such that the ecological benefit target requires the discharge flow to be maintained near the appropriate discharge, but this flow obviously cannot meet the flow requirements to produce as much power as possible. A specific analysis of the impact between objectives is described in detail below.

However, in the multi-objective optimization, the other benefit objectives except for power generation are improved, and the optimization effect is obvious, which shows that our model did optimize the scheduling methods. Besides, although part of the power generation lost, the increase in 
other benefits is more in line with the requirements of modern dispatching planning in the pursuit of comprehensive development.

\subsection{Objective Benefit and Multi-Objective Relation Analysis}

Through the calculation of the model, the multi-objective non-inferior solution sets of the reservoir system in the upper reaches of the Yangtze River under the conditions of wet, normal, and dry water are obtained, respectively (Figure 5). The non-inferior fronts are drawn in the three-dimensional coordinate system in which the three coordinate systems correspond to the objective values of power generation, ecology, and water supply, respectively, and the changes of the shipping target values are represented by color.

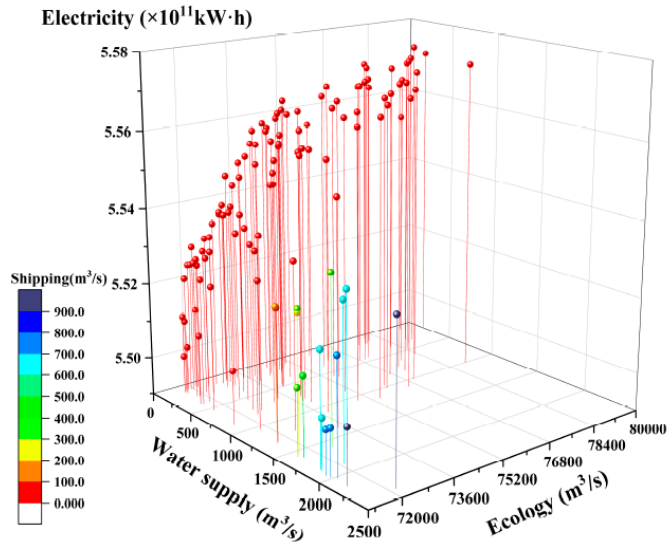

(a)

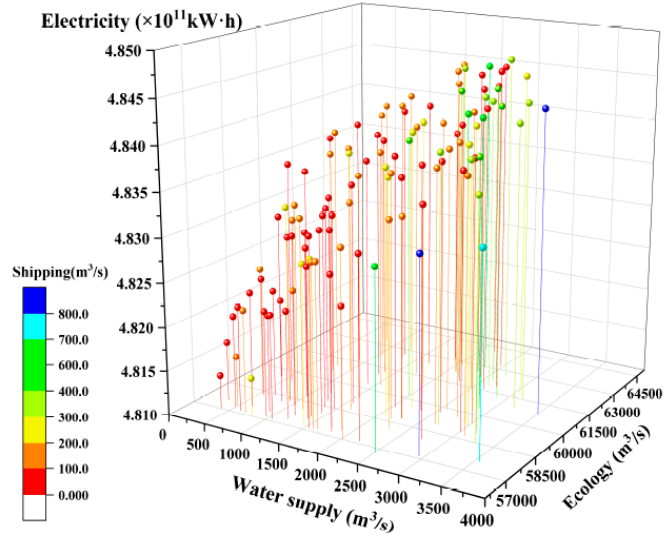

(b)

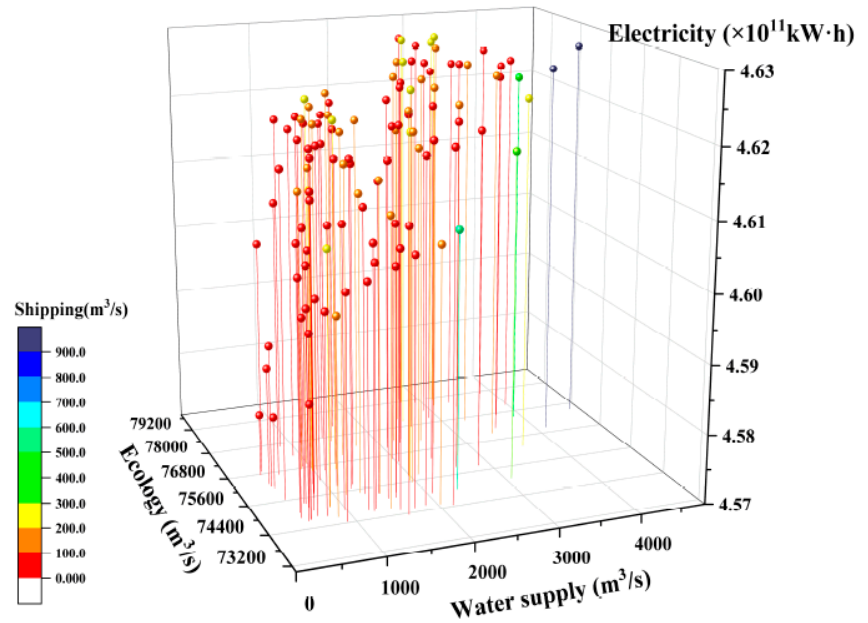

(c)

Figure 5. Non-inferior frontiers in wet, normal, and dry years considering flood control, power generation, ecology, water supply, and shipping in the upper Yangtze River using NSGA-III. (a) Wet year (1964); (b) normal year (1988); (c) dry year (1959).

There are obvious differences among the value and distribution of the objective function due to the difference of incoming water quantity (Table 6). 
Table 6. Range of the four objectives values in wet, normal, and dry years.

\begin{tabular}{ccccc}
\hline Objective & $\begin{array}{c}\text { Power Generation } / \times \\
\mathbf{1 0}^{\mathbf{1 1}} \mathbf{~} \mathbf{W} \cdot \mathbf{h}\end{array}$ & $\begin{array}{c}\text { Water } \\
\text { Shortage } / \mathbf{m}^{\mathbf{3}} / \mathbf{s}\end{array}$ & $\begin{array}{c}\text { Suitable Ecological Flow } \\
\text { Deviation } / \times \mathbf{1 0}^{\mathbf{4}} \mathbf{~ m}^{\mathbf{3}} / \mathbf{s}\end{array}$ & $\begin{array}{c}\text { Suitable Navigable } \\
\text { Flow Deviation } / \mathbf{m}^{\mathbf{3}} / \mathbf{s}\end{array}$ \\
\hline Year & $5.50-5.57$ & $39-2379$ & $7.1-7.9$ & $0-1131$ \\
net year (1964) & $4.81-4.85$ & $304-3495$ & $5.7-6.4$ & $0-888$ \\
normal year (1988) & $4.58-4.63$ & $387-4860$ & $7.4-8.2$ & $0-1080$ \\
\hline
\end{tabular}

It can be seen from the table that the power generation shows an obvious decreasing trend with the decrease of incoming water quantity. Adequate water inflow will contribute to the great efficiency of power generation by allowing a greater discharge flow when maintaining the same water level. The water shortage increased rapidly along with the water volume decreasing, while the ecological condition can be better met in the normal year as the inflow is closer to the requirements of the suitable ecological flow, and both cannot be fully satisfied due to the constraints of flood control and other objectives. For shipping objective, it was better met in the normal year, as the discharge may be better held between the upper and lower limits of shipping requirements, and it can be fully satisfied due the limit not being too tight as the expression of a flow range.

Each target has different responses in terms of the value and fluctuation range with the change of incoming water quantity. At the same time, the satisfaction or benefit of a goal is not only related to the goal itself, but also affected by other goals that need to be met.

In a dry year with less incoming water, the satisfaction degree of each goal is more seriously restricted by the water quantity, thus weakening the interactions among the goals themselves. According to Figure 6, the non-inferior solutions in the wet year and the normal year can be evenly distributed in space, and the performance in the wet year is better. Thus, the Pareto front of the wet year is projected onto 12 plane Cartesian coordinate systems, in which each has two targets as the coordinate axis.

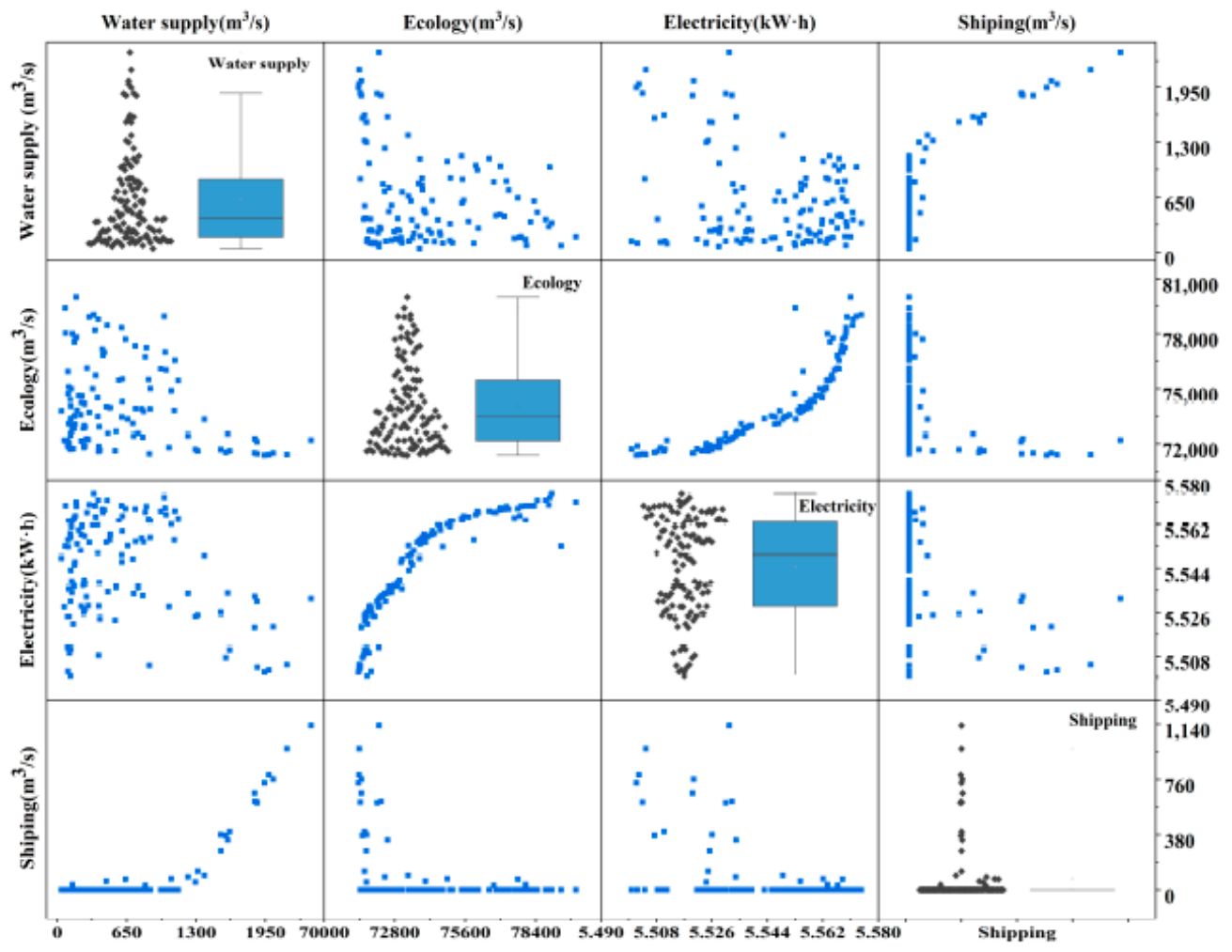

Figure 6. Matrix scatter diagram in a wet year to show the relationships among the four objectives of power generation, water supply, ecology, and shipping. 
It can be seen from Figure 6 that the ecological objective and power generation in the wet year show an obvious competitive relationship; with the increase of the total power generation, the satisfaction degree of suitable ecological flow decreases continuously. This is because in order to meet the requirements of ecological water demand, the reservoir needs to increase the discharge in the non-flood season to achieve the ecological suitable flow, which leads to the reservoir not being able to operate at a high water level during the dry season and causing the decrease of power generation; and in the flood season, the reservoir shall control the discharge flow to satisfy the ecological appropriate flow restriction, which hinders the power station from making maximum use of the large incoming water during the flood season. Therefore, the ecological benefits and power generation benefits of hydropower stations are contradictory and restricted. When the water supply shortage is below $1100 \mathrm{~m}^{3} / \mathrm{s}$ in Figure 6, the reservoir system can play its coordinating and dispatching role to ensure that the flow requirements of shipping are met to a greater extent, and at this time, the damage degree of shipping and water supply are both small. When the satisfaction degree of the shipping target decreases, the water supply shortage of the reservoir system has the same changing trend; that is to say, there is a certain synergy between them. The main reason is that the minimum water volume requirement of each water supply control station is less than the lower limit of the suitable flow of the river channel (except in the Three Gorges the former $\left(6000 \mathrm{~m}^{3} / \mathrm{s}\right)$ is slightly higher than the latter $\left.\left(5000 \mathrm{~m}^{3} / \mathrm{s}\right)\right)$. When the water supply cannot be satisfied, it means that the water supply in the river is insufficient; in this case, the minimum flow requirement of shipping is more likely to be damaged.

The matrix scatter diagram (Figure 6) also shows that in addition to the above groups of relationships, the pairwise relations between the other groups are scattered on the scatter point diagram. The main reason is that the relationship between these objectives is weak, and the competition for water demand is more complex when the four-dimensional benefit objectives and flood control requirements work together. This will be analyzed in detail in the following parts.

\subsection{Mechanism of Interaction among Multi-Objectives}

In order to study the mechanism of the interaction between the objectives in the multi-objective optimization problem, this study selected an equilibrium scheme on the Pareto front as a contrast, and discussed the variation of the other benefit target values when selecting the operation scheme in favor of one objective. This helps analyze how the benefit objectives interact with each other when meeting the requirements of flood control, so as to provide guidance for the operation of a reservoir group system in actual production.

There is no direct dominant relationship between the schemes in the Pareto non-inferior solution set, and each scheme corresponds to multiple attributes. Considering that the objectives interact with each other in this study, it is difficult to clearly define the conversion relationship between the objectives in a quantitative way, nor can we absolutely judge which benefit goal needs to be satisfied first. So, the fuzzy evaluation method is used to calculate the membership degree of each non-inferior solution with the indices of power generation, water shortage, suitable ecological flow deviation, and suitable navigable flow deviation so as to select the equilibrium solution among 120 non-inferior solutions. The position of the selected solutions on the Pareto frontier is shown in Figure 7. 


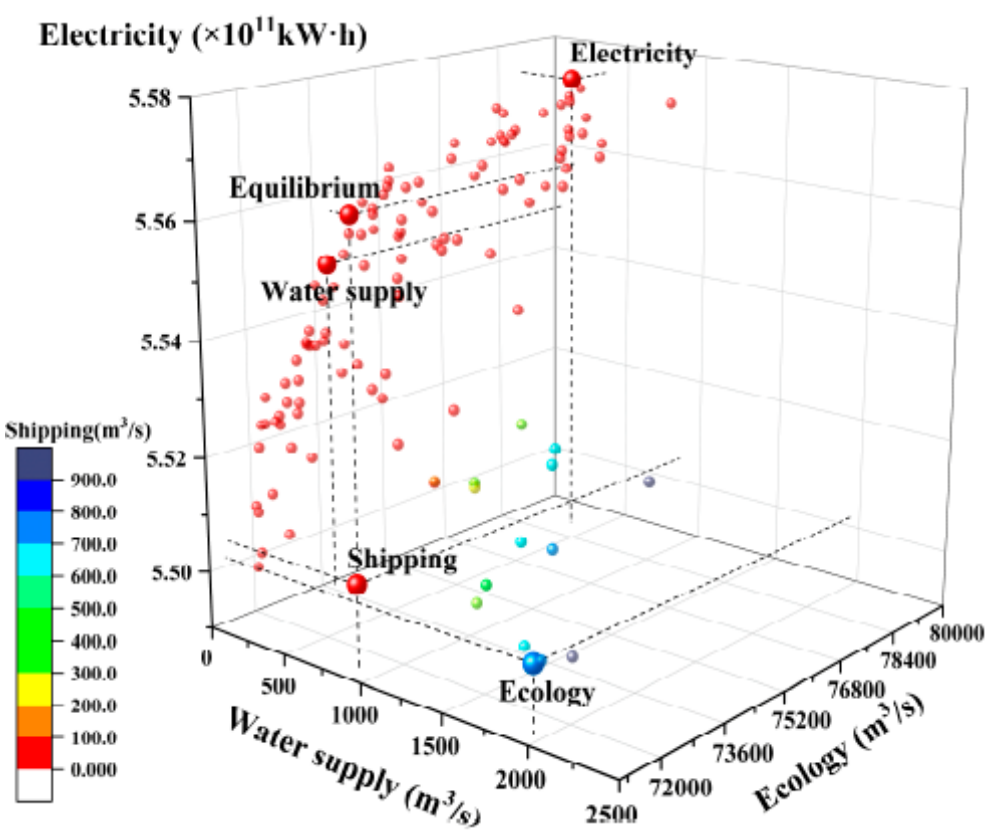

Figure 7. The equilibrium and other preferred solutions on the Pareto frontier.

Table 7 shows the changes of the four objectives under each preference scheme compared with the values of the objectives of the equilibrium solution, in which the power generation, water supply, and ecology are expressed in percentages, while the shipping is expressed as a specific value (the shipping conditions can be fully satisfied $\left(f_{4}=0\right)$ in the equilibrium solution, so it cannot be calculated in the form of a percentage). The positive number indicates that the target benefit is improved, while the negative number indicates that the benefit is reduced, and the degree of damage is increased.

Table 7. Changes of the four objectives under a preference scheme compared with the equilibrium solution.

\begin{tabular}{ccccc}
\hline Objective & $\begin{array}{c}\text { Power Generation/× } \\
\mathbf{1 0}^{\mathbf{1 1}} \mathbf{~ k W} \cdot \mathbf{h}\end{array}$ & $\begin{array}{c}\text { Water } \\
\text { Shortage } / \mathbf{m}^{\mathbf{3}} / \mathbf{s}\end{array}$ & $\begin{array}{c}\text { Suitable Ecological Flow } \\
\text { Deviation } / \times \mathbf{1 0}^{\mathbf{4}} \mathbf{~ m}^{\mathbf{3}} / \mathbf{s}\end{array}$ & $\begin{array}{c}\text { Suitable Navigable Flow } \\
\text { Deviation } / \mathbf{m}^{3} / \mathbf{s}\end{array}$ \\
\hline $\begin{array}{c}\text { Optimal power } \\
\text { generation }\end{array}$ & $0.32 \%$ & $-167.10 \%$ & $-6.76 \%$ & 0 \\
$\begin{array}{c}\text { Optimal water } \\
\text { supply }\end{array}$ & $-0.16 \%$ & $69.19 \%$ & $0.34 \%$ & 0 \\
Optimal ecology & $-0.99 \%$ & $-1413.62 \%$ & $3.60 \%$ & -736.86 \\
Optimal shipping & $-0.95 \%$ & $-572.87 \%$ & $3.50 \%$ & 0 \\
\hline
\end{tabular}

For the power generation objective, the shipping targets are less affected by it; as we can see, the suitable navigable flow deviation remains 0 in the partial power generation scheme. However, both the water supply and the ecological condition will be sacrificed due to generating more power, among which the damage degree of the water supply may be better than that of the ecology $(167.1 \%$ for water shortage and $6.67 \%$ for ecological deviation in the first scheme). On the one hand, the basic number of the water supply shortage in the equilibrium solution is small. This leads to the fact that although the benefit of water supply changes little in other schemes, the value is large when it is presented in percentage. On the other hand, in the dry season, in order to make the power generation in the system as large as possible, the discharge will be appropriately reduced to maintain the reservoir at high water head operation. At this time, if there is the case that $Q_{k t}>E_{i t}^{a p p}$, and the reservoir discharge is more closer to the $E_{i t}^{a p p}$, then the damage degree of the water supply will greatly increase compared with that of the ecology. In a word, the power generation target will restrict the satisfaction of the ecological and water supply objectives.

For the water supply objective, the reservoir cannot keep the high head operation for a long time in order to ensure the water supply during the dry season, and this may affect power generation. However, for the shipping objective, when $S U^{a p p}>Q_{k t}>S L^{a p p}$, both targets can be satisfied if $q_{t}<S U^{a p p}$; 
when $Q_{k t}<S L^{a p p}$, even $q_{t}>Q_{k t}$, navigation limits may be satisfied or destroyed. $\mathrm{n}$ this case, the amount of water in the system needs to be adjusted in order to meet both of the targets at the same time. That is why the navigation flow deviation can be maintained at zero in the partial water supply scheme.

When we take the ecological objectives into account, the relationship between them may be related to the relationship among the different water demands for each objective and the discharge of reservoirs. They may show a competitive or a synergistic relationship under different requirements and discharge conditions.

(i) When $Q_{k t}<E_{i t}^{a p p}$, if $E_{i t}^{a p p}>q_{t}>Q_{k t}$, the damage to both is small; if $q_{t}<Q_{k t}$, the damage degree increases to both; if $q_{t}>>E_{i t}^{a p p}$, the damage to the ecology increases, but is not caused by the requirement of water supply. So, the two assume a cooperative relationship in this case.

(ii) When $Q_{k t}>E_{i t}^{a p p}$, if $q_{t}>Q_{k t}$, the requirement of water supply can be satisfied, but the damage to ecology will increase; if $E_{i t}^{a p p}<q_{t}<Q_{k t}$, the opposite is true. In this case, there is a competitive relationship between them. However, when $q_{t}<E_{i t}^{a p p}$, the damage degree increases to both, which means that they have a cooperative relationship.

It can be found that if the discharge is controlled within a certain range, a co-win between the two targets will be achieved. According to the analysis above, when $Q_{k t}>E_{i t}^{a p p}$ in a certain calculation period, the range of discharge flow needs to be controlled more strictly, as the effect of different flow processes on the degree of satisfaction of the two objectives is large in such cases. In the reservoir system of the upper reaches of the Yangtze River, this case occurred at the downstream section of Pubugou and the Three Gorges during the second to fourth period (from December to February). The discharge hydrograph line of the two reservoirs is shown in Figure 8. In the partial water supply scheme, the dispatching mode will give priority to the water supply, and then the reservoirs make the discharge as close as possible to the ecologically suitable flow on the premise of ensuring a small degree of water supply damage. Therefore, when the water supply requirement is prior, the water supply benefit and ecological benefit both increased compared with the equilibrium scheme. While the ecological objective is prior, the reservoir discharge will be closer to the suitable ecological flow. If the ecological suitable flow is much less than the water supply demand during that calculation period, there will be a large difference between the water supply and water demand, and the satisfaction of water supply will decrease greatly.

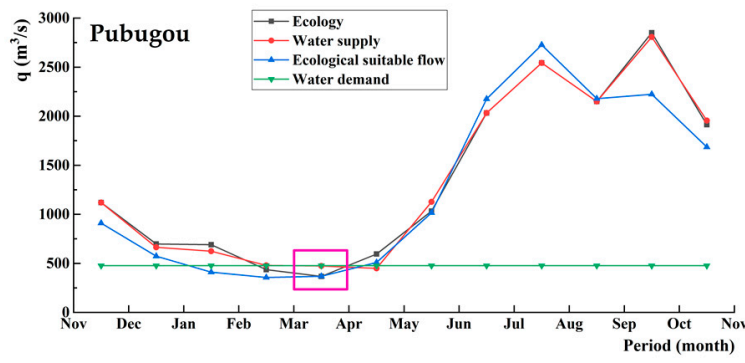

(a)

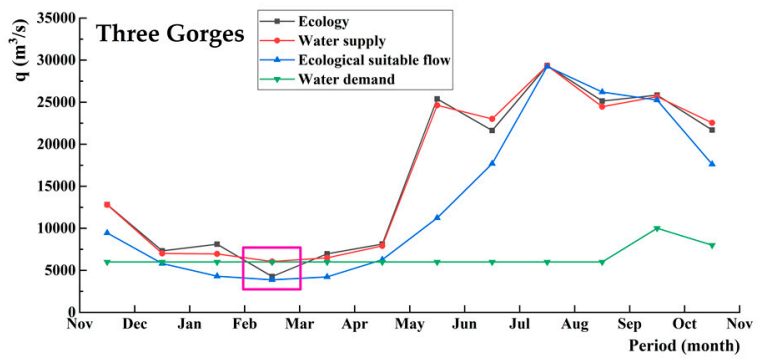

(b)

Figure 8. The discharge hydrograph line of Pubugou and the Three Gorges in a partial water supply scheme and partial ecology scheme compared with the ecological and water supply requirements. (a) Pubugou; (b) the Three Gorges.

For the ecological scheme, it affects power generation obviously; as the amount of power decreases the most among all the four schemes, the competitive relationship between ecology and power generation is strong. The satisfaction of the shipping target will be destroyed when $E_{i t}^{a p p}<S L^{a p p}$. Thus, the strict control conditions of the ecological objectives on discharge are the main factor that restricts the development of the reservoir in meeting the multi-benefit goal.

For shipping objective, the wide range of shipping constraints means that the reservoirs have no need to increase discharge or maintain high water level operation, which results in the reduction 
of power generation. As to the water supply objective, when $Q_{k t}>S L^{a p p}$, the $q_{t}$ may not meet the water supply demand when meeting shipping requirements, so the water supply benefits decrease in the fourth scheme; for the ecological objective, if $S U^{a p p}>E_{i t}^{a p p}>S L^{a p p}$, then the ecological demand is easier to be satisfied, if $E_{i t}^{a p p}<S L^{a p p}$, the reservoir can also make the discharge as close to the ecological suitable discharge as possible on the basis of meeting the shipping requirement, thus increasing the ecological benefits. In the case of abundant water over the whole year, the impact of shipping on other objectives is relatively small, and it plays a limited role in restricting comprehensive optimization. The impact of shipping on other objectives is relatively small, and it plays a limited role in restricting comprehensive optimization.

Table 8 shows the interaction effect and the strength of the relationship among the four objectives. In multi-objective optimization, there are competitive relationships between power generation and other objectives, and there is no win-win situation. When considering other objectives, the reservoir will always sacrifice the amount of power generation. The relationship between water supply and ecology is affected by some reservoirs with complex discharge requirements for these two objectives. The main restriction of water supply objective and ecological objective is from power generation. Meanwhile, the relationship between shipping and other objectives is not obvious. Under the premise of satisfying shipping conditions, other targets are not obviously restricted, and can be brought into full play through the water distribution function in the system.

Table 8. Interaction relationship between the four benefit objectives.

\begin{tabular}{|c|c|c|c|c|}
\hline Objective & Power Generation & Water Supply & Ecology & Shipping \\
\hline Power generation & 1 & moderate $^{1}$ & high $^{1}$ & low 1 \\
\hline Water supply & moderate & 1 & no conflict /low 2 & low \\
\hline Ecology & high & no conflict $/$ low $^{2}$ & 1 & low \\
\hline Shipping & low & low & low & 1 \\
\hline
\end{tabular}

In the actual operation of the reservoir, the main purpose of reservoir operation during the water supply period is to ensure the satisfaction of the water supply demand in the basin. At this time, the power generation function of the reservoir needs to make concessions. In other periods, with the increasing demand for ecological environment today, the reservoir group cannot blindly increase power generation, but must sacrifice part of the electrical function to meet the flow limitations in ecological sections. At the same time, it is necessary to weigh the requirements of water supply objectives and ecological objectives for reservoirs and the importance of these two objectives to the region in order to reasonably control the discharge of reservoirs to reduce the total benefit loss when there is a contradictory relationship between ecology and water supply objectives.

In addition, this study also considered the limitation of flood control to reservoir operation. The main task of reservoirs in the flood season is to ensure the safety of the dam and downstream basin. During this period, the importance of the flood control function is greater than all the other objectives, and the reservoirs must follow the principle of flood control. In the flood season, the demand of power generation and water supply can always be met, but the ecological and shipping conditions are easy to be destroyed. Therefore, on the basis of ensuring the safety of flood control in flood season operation, it is necessary to focus more on meeting the ecological and shipping requirements in order to increase the total benefit of the reservoir system.

\subsection{Analysis on the Advantages of Joint Optimization of Reservoir Group System}

In view of the disadvantages of dividing the upper reaches of the Yangtze River into several sub-basins in existing studies, a giant reservoir group system considering the joint operation of 30 reservoirs in this area is constructed in order to study the advantages of joint operation of giant-scale 
systems and the interaction between reservoirs. Table 9 shows the values of the four benefit targets under the condition of joint operation and separate operation.

Table 9. Comparison of benefit targets of the system under different operation schemes.

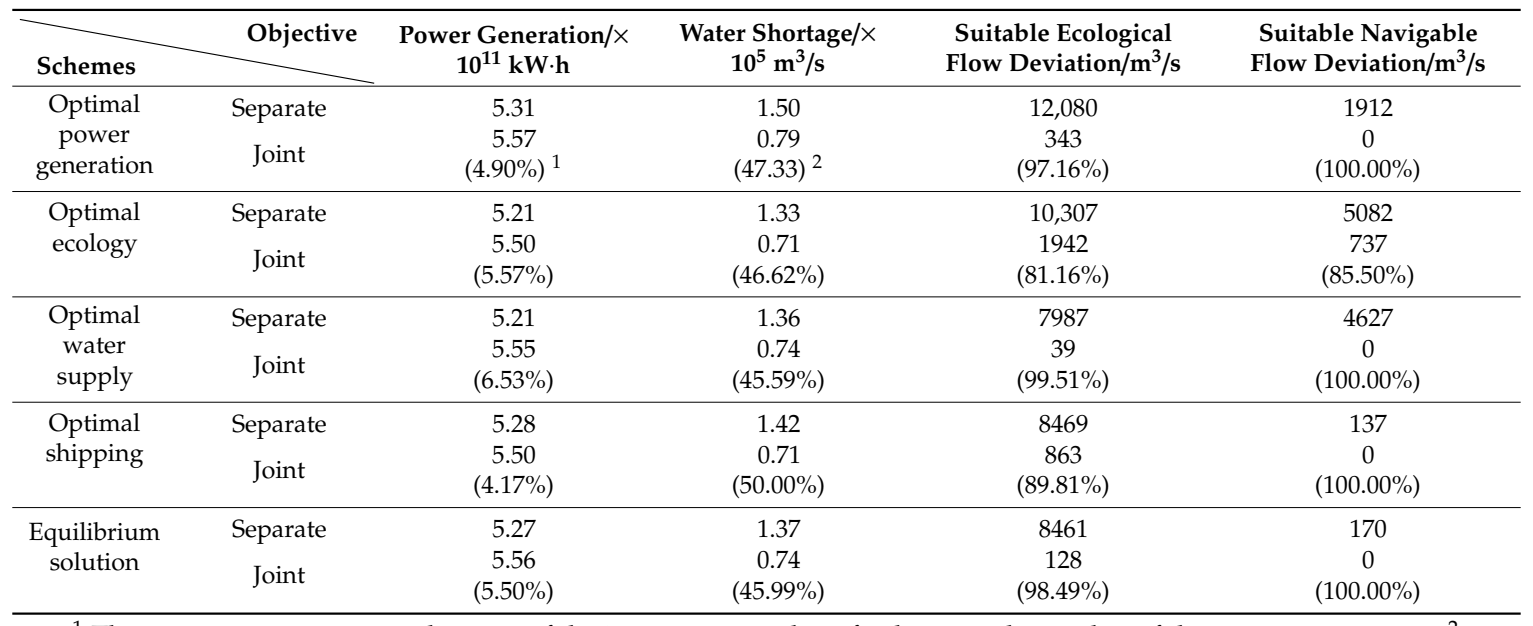

${ }^{1}$ The percentage represents the ratio of the joint operation benefit change value to that of the separate operation. ${ }^{2}$ The positive percentage indicates that the target benefit is increased.

It can be seen from the table that no matter which benefit the system favors, the value of each benefit target of joint operation is better than that of separate operation. This shows that in joint dispatching, through the redistribution of water volume in time and space, the requirements of the whole system for various benefit objectives can be better met, the reservoir capacity of all reservoirs in the system can be fully utilized, and the discarded water in flood season can be reduced, so as to compensate for the insufficiency of water volume of other reservoirs in the system and alleviate the excessive discharge of some reservoirs in some periods. As a result, the overall benefit of the reservoir system has been improved. Especially for reservoirs with a large regulating capacity on the main stream, branch reservoirs can store or discharge branch inflow rationally to make up for the shortage of downstream water or control the water volume to avoid excessive discharge. So, the flow and head of the reservoir with strong regulation ability and great benefit responsibility can be maintained in a range that can not only increase power generation but also better meet the needs of ecology, water supply, and shipping.

Take the Three Gorges as the example, as the most important controlled reservoir in the middle and upper reaches of the Yangtze River, the response of the Three Gorges' benefit objectives is the most representative and valuable. This study compared its performances of each benefit objective under two schemes in the wet year. Scheme 1 was the single reservoir operation of the Three Gorges Reservoir, and the inflow was the natural runoff process from the upper reaches of the Three Gorges in 1964. Scheme 2 was the joint operation of the reservoir system in the upper reaches of the Yangtze River, and the inflow had been regulated by the controlled reservoirs on the main and tributaries of the Yangtze River in the upstream of the Three Gorges. This research analyzes and compares the values of the four benefit targets under different scheduling schemes, and the results are shown in Table 10. 
Table 10. Comparison of benefit targets of the Three Gorges under different operation schemes.

\begin{tabular}{|c|c|c|c|c|c|}
\hline Schemes & Objective & $\begin{array}{c}\text { Power Generation/× } \\
10^{11} \mathrm{~kW} \cdot \mathrm{h}\end{array}$ & $\begin{array}{l}\text { Water Shortage } / \times \\
10^{5} \mathrm{~m}^{3} / \mathrm{s}\end{array}$ & $\begin{array}{l}\text { Suitable Ecological } \\
\text { Flow Deviation } / \mathrm{m}^{3} / \mathrm{s}\end{array}$ & $\begin{array}{l}\text { Suitable Navigable } \\
\text { Flow Deviation } / \mathrm{m}^{3} / \mathrm{s}\end{array}$ \\
\hline \multirow{2}{*}{$\begin{array}{l}\text { Optimal power } \\
\text { generation }\end{array}$} & Single & 1.13 & 10,152 & 1.12 & 1691 \\
\hline & Joint & $\begin{array}{c}1.15 \\
(1.77 \%)^{1}\end{array}$ & $\begin{array}{c}79 \\
(99.22 \%)^{2}\end{array}$ & $\begin{array}{c}0.43 \\
(61.61 \%)\end{array}$ & $\begin{array}{c}0 \\
(100.00 \%)\end{array}$ \\
\hline \multirow{2}{*}{$\begin{array}{l}\text { Optimal } \\
\text { ecology }\end{array}$} & Single & 1.07 & 8045 & 0.99 & 5000 \\
\hline & Joint & $\begin{array}{c}1.14 \\
(6.54 \%)\end{array}$ & $\begin{array}{c}639 \\
(92.06 \%)\end{array}$ & $\begin{array}{c}0.38 \\
(61.62 \%)\end{array}$ & $\begin{array}{c}0 \\
(100.00 \%)\end{array}$ \\
\hline $\begin{array}{l}\text { Optimal water } \\
\text { supply }\end{array}$ & Joint & $\begin{array}{c}1.14 \\
(3.64 \%)\end{array}$ & $\begin{array}{c}0 \\
(100.00 \%)\end{array}$ & $\begin{array}{c}0.43 \\
(59.43 \%)\end{array}$ & $\begin{array}{c}0 \\
(100.00 \%)\end{array}$ \\
\hline \multirow{2}{*}{$\begin{array}{l}\text { Optimal } \\
\text { shipping }\end{array}$} & Single & 1.12 & 8628 & 1.08 & 137 \\
\hline & Joint & $\begin{array}{c}1.14 \\
(1.79 \%)\end{array}$ & $\begin{array}{c}204 \\
(97.64 \%)\end{array}$ & $\begin{array}{c}0.38 \\
(64.81 \%)\end{array}$ & $\begin{array}{c}0 \\
(100.00 \%)\end{array}$ \\
\hline
\end{tabular}

${ }^{1}$ The percentage represents the ratio of the joint operation benefit change value of the Three Gorges to that of the separate operation. ${ }^{2}$ The positive percentage indicates that the target benefit is increased.

Table 8 shows that the value of each benefit objective in the joint scheduling of the Three Gorges Reservoir is better than or equal to the corresponding value of the single reservoir operation. This result proves that the compensation and regulation between hydropower stations in the system has been brought into full play in the joint integrated operation of reservoir groups. The upstream hydropower station compensates the downstream of the whole system by sacrificing a part of its own benefits. By adjusting the space-temporal distribution of incoming water, it can ensure that the downstream power station, especially the control reservoir with a great regulation capacity, which has an important position in power generation and water supply, can operate at a reasonable water level interval, give full play to the regulation and storage function of the reservoir, and reasonably distribute the uneven water inflow process that is not conducive to the benefit throughout the year. As a result, the downstream reservoir can freely adjust the discharge flow process of the reservoir according to the water demand of the other benefit targets, so as to increase its own benefit as well as that to the overall system.

This paper shows the water-level change process of 20 reservoirs in the upper reaches of the Yangtze River when biased toward different benefit objectives in the wet year, together with the equilibrium solution (Figure 9). It can be seen from the diagram that the variation range and amplitude of the water level of each tributary leading the reservoirs in equilibrium solution are large due to the small influence of other reservoir operation modes, but the water-level change of the reservoir in the downstream position is much more stable. In addition, the water-level change of each reservoir in the equilibrium solution is basically kept between the upper and lower outer lines of the range of water-level variation when partial to the single-target solution. The results above, on the one hand, show that the equilibrium solution does play a role in coordinating the benefit objectives and reflects the influence of each objective on reservoir operation in the case of multi-objective comprehensive optimization. On the other hand, it also shows the characteristics of the interaction between the reservoirs in the reservoir system. 
$\rightarrow$ Electricity $\rightarrow$ Ecology $\rightarrow$ Water supply $\rightarrow$ Shipping $*$ Equilibrium
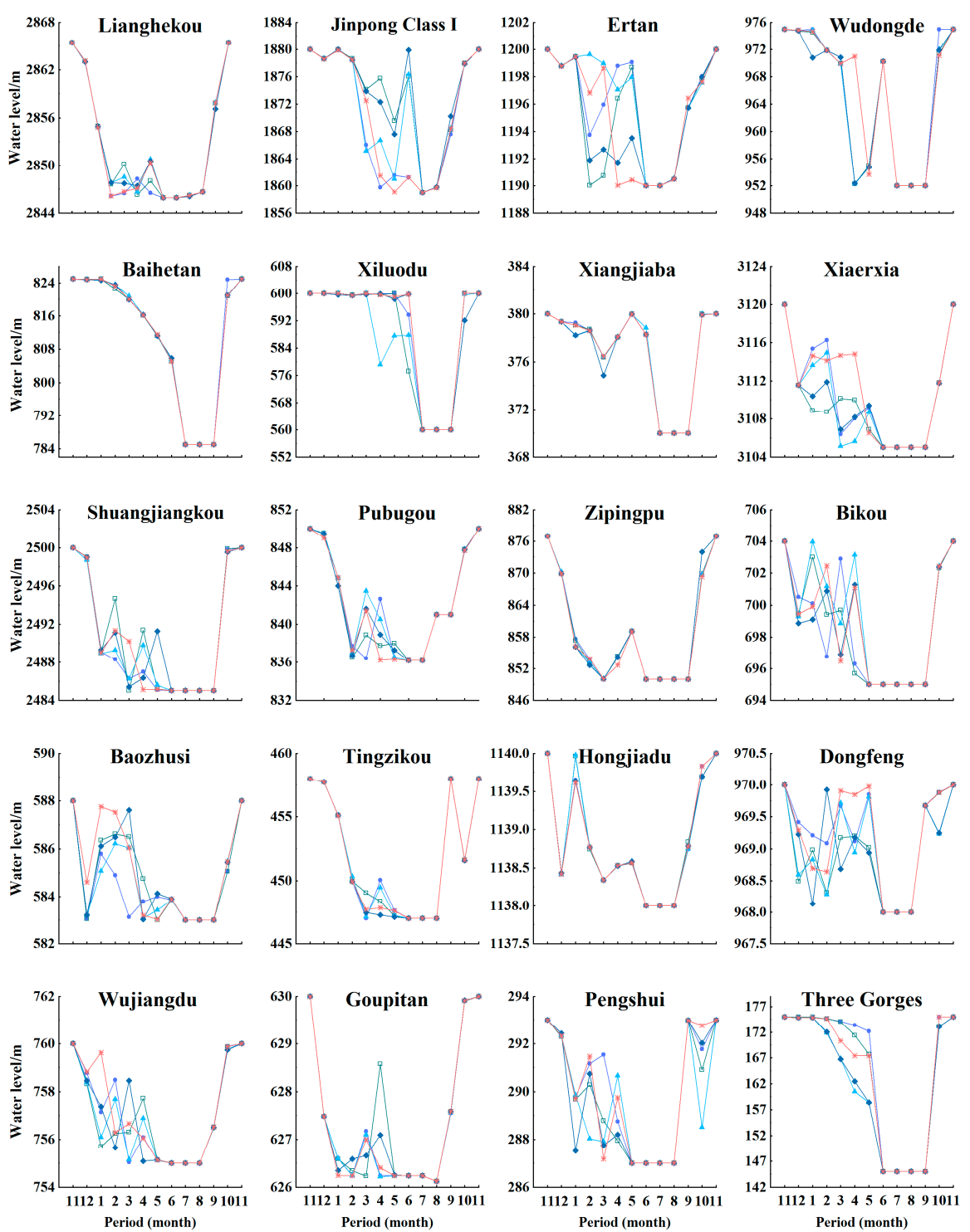

Figure 9. The water-level process line of each reservoir under different partial schemes.

\section{Conclusions}

Taking the reservoir system composed of 30 controlled reservoirs in the upper reaches of the Yangtze River as the research object under the condition of ensuring the restriction of flood control, this paper discusses the competitive relationship among the four benefit objectives of power generation, ecology, water supply, and shipping under the constraint of flood control and draws the following conclusions:

(1). Power generation is the main factor that restricts the other benefit functions of the reservoir, and is restricted by them. During reservoir operation, it is more likely to sacrifice part of power generation to improve the satisfaction of other benefits, among which the competitive relationship with ecological objectives is the most obvious; there may be a competitive or synergistic relationship between water supply and ecology under different water supply and ecological demands; the shipping objective plays a limited role in restricting the realization of other objectives, and the degree of influence from other objectives is also small compared with the intensity of competition among other objectives. 
(2). The benefit value of joint operation is greater than that of the separate operation, which is reflected in the four objectives of power generation, ecology, water supply, and shipping. This is mainly because in the joint operation, the water volume in the system has more room for distribution in time and space. In addition, the operation of the downstream reservoirs will be affected by the upstream reservoirs schedule because of the hydraulic connection that exists between the upstream and downstream reservoirs. Reservoirs with larger water volume can supplement the shortage of other reservoirs and reduce the wastewater in the system. Furthermore, reservoirs with a strong regulation ability and large utilizable capacity, such as the Three Gorges Reservoir, perform better in joint dispatching. This reflects the compensation and regulation function of hydropower station systems in the integrated operation of reservoir groups.

This study shows the possibility of increasing the comprehensive benefits of the giant reservoir system in the upstream of the Yangtze River, which matches the development requirements of our country. This modeling method and analysis idea can also be applied to other river basins and reservoir systems in order to promote local development and fully excavate the utilization value of water resources.

However, there is still a need for improvement in this study. Some more refined quantitative analysis methods can be used to analyze the relationship between the four benefit objectives. In addition, the flood control may be regarded as one of the research objectives, and the refined dispatching mode with smaller step size in the flood season can be studied to optimize the benefit of the reservoir system throughout the year. Furthermore, the hydraulic model and hydrological model can be combined to deepen the thinking of the multi-objective optimization problem.

Author Contributions: Conceptualization, M.C.; Formal analysis, M.C.; Funding acquisition, Z.D.; Methodology, M.C.; Project administration, Z.D. and W.J.; Software, M.C., X.N. and W.J.; Supervision, Z.D., W.J.; Validation, X.N.; Visualization, M.C. and H.Y.; Writing-original draft, M.C.; Writing-review \& editing, M.C. and W.J.

Funding: This research was funded by the National Key Research and Development Project of China, grant number 2016YFC0402209.

Conflicts of Interest: The authors declare no conflict of interest.

\section{References}

1. Duan, C.; Chen, B. Energy-Water nexus of international energy trade of China. Appl. Energy 2017, 194, 725-734. [CrossRef]

2. Giuliani, M.; Anghileri, D.; Castelletti, A.; Vu, P.N.; Soncini-Sessa, R. Large storage operations under climate change: Expanding uncertainties and evolving tradeoffs. Environ. Res. Lett. 2016, 11, 35009. [CrossRef]

3. Chang, X.; Liu, X.; Zhou, W. Hydropower in China at present and its further development. Energy 2010, 35, 4400-4406. [CrossRef]

4. Wang, X.; Chang, J.; Meng, X.; Wang, Y. Short-term hydro-thermal-wind-photovoltaic complementary operation of interconnected power systems. Appl. Energy 2018, 229, 945-962. [CrossRef]

5. Uen, T.; Chang, F.; Zhou, Y.; Tsai, W. Exploring synergistic benefits of Water-Food-Energy Nexus through multi-objective reservoir optimization schemes. Sci. Total Environ. 2018, 633, 341-351. [CrossRef]

6. Meng, X.; Chang, J.; Wang, X.; Wang, Y. Multi-objective hydropower station operation using an improved cuckoo search algorithm. Energy 2019, 168, 425-439. [CrossRef]

7. Bozorg-Haddad, O.; Janbaz, M.; Loáiciga, H.A. Application of the gravity search algorithm to multi-reservoir operation optimization. Adv. Water Resour. 2016, 98, 173-185. [CrossRef]

8. Nagesh Kumar, D.; Janga Reddy, M. Multipurpose Reservoir Operation Using Particle Swarm Optimization. J. Water Res. Plan. Manag. 2007, 133, 192-201. [CrossRef]

9. Afshar, M.H. Large scale reservoir operation by Constrained Particle Swarm Optimization algorithms. J. Hydro Environ. Res. 2012, 6, 75-87. [CrossRef]

10. Lu, B.; Li, K.; Zhang, H.; Wang, W.; Gu, H. Study on the optimal hydropower generation of Zhelin reservoir. J. Hydro Environ. Res. 2013, 7, 270-278. [CrossRef] 
11. Islam, S.; Talukdar, B. Application of artificial immune system in optimization of reservoir operation. Int. J. Water Resour. Manag. 2012, 3, 241-254.

12. Zhang, Z.; Zhang, S.; Wang, Y.; Jiang, Y.; Wang, H. Use of parallel deterministic dynamic programming and hierarchical adaptive genetic algorithm for reservoir operation optimization. Comput. Ind. Eng. 2013, 65, 310-321. [CrossRef]

13. Chang, J.; Meng, X.; Wang, Z.; Wang, X.; Huang, Q. Optimized cascade reservoir operation considering ice flood control and power generation. J. Hydrol. 2014, 519, 1042-1051. [CrossRef]

14. Yaseen, Z.; Allawi, M.; Karami, H.; Ehteram, M.; Farzin, S.; Najah, A.; Koting, S.; Mohd, N.; Jaafar, W.; Afan, H.; et al. A hybrid bats-Warm algorithm for optimizing dam and reservoir operation. Neural Comput. Appl. 2019, 31, 8807-8821. [CrossRef]

15. Karami, H.A.E.M. Optimization of energy management and conversion in the water systems based on evolutionary algorithms. Neural Comput. Appl. 2019, 31, 5951-5964. [CrossRef]

16. Ehteram, M.; Mousavi, S.; Karami, H.; Farzin, S.; Emami, M.; Binti Othman, F.; Amini, Z.; Kisi, O.; El-Shafie, A. Fast convergence optimization model for single and multi-purposes reservoirs using hybrid algorithm. Adv. Eng. Inform. 2017, 32, 287-298. [CrossRef]

17. Zitzler, E.; Thiele, L. An evolutionary algorithm for multiobjective optimization: The strength Pareto approach. In Computer Engineering and Networks Laboratory (TIK); Swiss Federal Institute of Technology Zürich (ETH): Zürich, Switzerland, 1998.

18. Deb, K.; Jain, H. An Evolutionary Many-Objective Optimization Algorithm Using Reference-Point-Based Nondominated Sorting Approach, Part I: Solving Problems with Box Constraints. IEEE Trans. Evol. Comput. 2014, 18, 577-601. [CrossRef]

19. Cheng, W.; Huang, C.; Hsu, N.; Wei, C. Risk Analysis of Reservoir Operations Considering Short-Term Flood Control and Long-Term Water Supply: A Case Study for the Da-Han Creek Basin in Taiwan. Water 2017, 9 , 424. [CrossRef]

20. Tilmant, A.; Goor, Q.; Pinte, D. Agricultural-to-hydropower water transfers: Sharing water and benefits in hydropower-irrigation systems. Hydrol. Earth Syst. Sci. 2009, 13, 1091-1101. [CrossRef]

21. Wu, Y.; Chen, J. Estimating irrigation water demand using an improved method and optimizing reservoir operation for water supply and hydropower generation: A case study of the Xinfengjiang reservoir in southern China. Agric. Water Manag. 2013, 116, 110-121. [CrossRef]

22. Si, Y.; Li, X.; Yin, D.; Li, T.; Cai, X.; Wei, J.; Wang, G. Revealing the water-energy-food nexus in the Upper Yellow River Basin through multi-objective optimization for reservoir system. Sci. Total Environ. 2019, 682, 1-18. [CrossRef] [PubMed]

23. Veintimilla-Reyes, J.; De Meyer, A.; Cattrysse, D.; Tacuri, E.; Vanegas, P.; Cisneros, F.; Van Orshoven, J. MILP for Optimizing Water Allocation and Reservoir Location: A Case Study for the Machángara River Basin, Ecuador. Water 2019, 11, 1011. [CrossRef]

24. Wu, L.; Bai, T.; Huang, Q.; Wei, J.; Liu, X. Multi-Objective Optimal Operations Based on Improved NSGA-II for Hanjiang to Wei River Water Diversion Project, China. Water 2019, 11, 1159. [CrossRef]

25. Alahdin, S.; Ghafouri, H.R.; Haghighi, A. Multi-reservoir System Operation in Drought Periods with Balancing Multiple Groups of Objectives. KSCE J. Civ. Eng. 2019, 23, 914-922. [CrossRef]

26. Yang, G.; Guo, S.; Liu, P.; Li, L.; Xu, C. Multiobjective reservoir operating rules based on cascade reservoir input variable selection method. Water Resour. Res. 2017, 53, 3446-3463. [CrossRef]

27. Chen, M.; Chen, G.; Chen, J.; Fang, Q. Practices and achievements of multi-reservoir-joint dispatching in the upper reaches of the Yangtze River in 2018. China Flood Drought Manag. 2019, 29, 6-9.

28. Huang, L.; Li, X.; Fang, H.; Yin, D.; Si, Y.; Wei, J.; Liu, J.; Hu, X.; Zhang, L. Balancing social, economic and ecological benefits of reservoir operation during the flood season: A case study of the Three Gorges Project, China. J. Hydrol. 2019, 572, 422-434. [CrossRef]

29. Liu, X.; Lu, C.; Zhu, Y.; Singh, V.P.; Geng, Q.; Guo, X. Multi-objective reservoir operation during flood season considering spillway optimization. J. Hydrol. 2017, 552, 554-563. [CrossRef]

30. Zhou, Y.; Guo, S.; Xu, C.Y.; Pan, L.; Hui, Q. Deriving joint optimal refill rules for cascade reservoirs with multi-objective evaluation. J. Hydrol. 2015, 524, 166-181. [CrossRef]

31. Jia, W.; Dong, Z.; Duan, C.; Ni, X.; Zhu, Z. Ecological reservoir operation based on DFM and improved PA-DDS algorithm: A case study in Jinsha river, China. Hum. Ecol. Risk Assess. Int. J. 2019, 1-19. [CrossRef] 
32. Wang, X.M.; Zhou, J.Z.; Ou Yang, S.; Zhang, Y.C. TGC eco-friendly generation multi-objective optimal dispatch model and its solution algorithm. J. Hydraul. Eng. 2013, 44, 154-163.

33. Lu, Y.L.; Zhou, J.Z.; Wang, H.; Zhang, Y.C. Multi-objective optimization model for ecological operation in Three Gorges cascade hydropower stations and its algorithms. Adv. Water Sci. 2011, 22, 780-788.

34. Zhou, J.; Li, C.; Chen, F.; Zhang, Y. Integrated utilization of the Three Gorges Cascade for navigation and power generation in flood season. J. Hydraul. Eng. 2017, 48, 31-40.

35. Zhou, J.; Zhang, Y.; Zhang, R.; Ouyang, S.; Wang, X.; Liao, X. Integrated optimization of hydroelectric energy in the upper and middle Yangtze River. Renew. Sustain. Energy Rev. 2015, 45, 481-512. [CrossRef]

36. Jin, N.I.; Cui, S.; Tian, L.I.; Jin, L. On water demand of river ecosystem. J. Hydraul. Eng. 2002, 9, 14-26.

37. Das, I.; Dennis, J.E. Normal-Boundary Intersection: A New Method for Generating the Pareto Surface in Nonlinear Multicriteria Optimization Problems. SIAM J. Optim. 1998, 8, 631-657. [CrossRef]

38. Ni, X.; Dong, Z.; Xie, W.; Jia, W.; Duan, C.; Yao, H. Research on the Multi-Objective Cooperative Competition Mechanism of Jinsha River Downstream Cascade Reservoirs during the Flood Season Based on Optimized NSGA-III. Water 2019, 11, 849. [CrossRef]

39. Chen, C.; Yuan, Y.; Yuan, X. An Improved NSGA-III Algorithm for Reservoir Flood Control Operation. Water Resour. Manag. 2017, 31, 4469-4483. [CrossRef]

40. Tian, Y.; Cheng, R.; Zhang, X.; Jin, Y. PlatEMO: A MATLAB Platform for Evolutionary Multi-Objective Optimization [Educational Forum]. IEEE Comput. Intell. Mag. 2017, 12, 73-87. [CrossRef]

41. Zitzler, E.; Thiele, L.; Laumanns, M.; Fonseca, C.M.; Da Fonseca, V.G. Performance assessment of multiobjective optimizers: An analysis and review. IEEE Trans. Evol. Comput. 2003, 7, 117-132. [CrossRef]

42. Fleischer, M. The Measure of Pareto Optima Applications to Multi-Objective Metaheuristics; Evolutionary Multi-Criterion Optimization: Berlin/Heidelberg, Germany, 2003; pp. 519-533.

(C) 2019 by the authors. Licensee MDPI, Basel, Switzerland. This article is an open access article distributed under the terms and conditions of the Creative Commons Attribution (CC BY) license (http://creativecommons.org/licenses/by/4.0/). 